Research Article

\title{
The use of routine chemoprophylaxis for deep vein thrombosis in all patients undergoing hip and knee replacements in rural population - whether it is justified?
}

\author{
Nakul S. Chandak*, Shreyas Gandhi, Biren Patel, Yograj Rathwa
}

Department of Orthopedics, C U Shah Medical College, Surendranagar, Gujarat, India

Received: 30 May 2013

Accepted: 14 June 2013

*Correspondence to:

Dr. Nakul S. Chandak,

Email: nakul04@gmail.com

(C) 2013 Chandak NS et al. This is an open-access article distributed under the terms of the Creative Commons Attribution License, which permits unrestricted use, distribution, and reproduction in any medium, provided the original work is properly cited.

\begin{abstract}
Background: Deep vein thrombosis (DVT)/ pulmonary embolism (PE) are one of the most feared complications in patients undergoing joint replacements in western literatures. The exact incidence of DVT in Indians particularly rural population remains debatable. Also ways to prevent it in rural population is a dilemma for the orthopedic community. Hence this study was undertaken.

Methods: We carried a prospective study of 135 cases of joint replacements i.e. 78 of total hip replacements and 57 of total knee replacements. None of the patients were given any form of chemoprophylaxis like low molecular weight heparin (LMWH). Strict monitoring was done. All patients underwent duplex ultrasonographic doppler assessment of both the lower limbs between the 4th-7th day and on 14th - 16th postoperative day. Only 5 out of 135 cases had DVT. Results: We observed that DVT developed more commonly following total hip replacement surgery (4 cases) as compared to total knee replacement (1 case). There was no mortality in our study.

Conclusions: DVT following total joint replacements in rural Indian patients is not as common as reported in the Western literature. A high level of suspicion and close clinical monitoring is mandatory. The use of routine chemoprophylaxis in every patient is perhaps not justified. In future further more trials with a larger number of patients and at multiple centers would be required to confirm the findings of our study and to formulate guidelines to prevent DVT.
\end{abstract}

Keywords: Deep vein thrombosis, Low molecular weight heparin, DVT, LMWH, Joint replacement

\section{INTRODUCTION}

Deep vein thrombosis (DVT) refers to the formation of thrombus within the deep vein, commonly in the calf and proximal deep veins of the thigh. If left untreated $30 \%$ of the calf thrombi extend into the proximal veins of the thigh. These proximal thrombi may be associated with $50 \%$ increased risk of pulmonary embolism (PE). Pulmonary embolism can cause severe morbidity as well as mortality.

Patients of total hip and knee replacements are considered at high risk Deep vein thrombosis, low molecular weight heparin, DVT, LMWH, joint replacement for developing DVT as any of the 3 major contributing factors in pathogenesis of DVT (venous stasis, hypercoagulability $\&$ vessel wall injury-Virchow's triad) can be activated during and after surgery. In western countries postoperative DVT is a well recognized complication of major lower limb surgery, incidence ranging from 32$84 \% .{ }^{1,20,23}$ One of the most feared complications of DVT is pulmonary embolism, which carries a considerable mortality rate. Another important complication is venous insufficiency, which may cause symptoms in the leg in $60 \%$ of patients. The clinical assessment of these complications is unreliable and the majority of venous thromboembolic events are asymptomatic. Even for an asymptomatic DVT, the risk of PE is considerable. Many DVTs, may however resolve spontaneously without further sequelae. In at least $10 \%$ of patients with symptomatic PE the death occur within a few hours, before diagnostic and therapeutic action can be taken. The risk of DVT extend for at least 3 months after surgery, the risk is maximum at 2-5 days postoperatively. Second peak occurs around $10-13^{\text {th }}$ day.

Among various modalities used for diagnosis of DVT, Color Doppler ultrasonography has the advantage of 
being noninvasive, cost effective, can be repeated when required, has no side effects, and matches venography in sensitivity and specificity as far as proximal DVT is concerned. $^{24}$

The incidence of DVT in Indian context is debatable especially in rural population. The reported incidence of DVT is based on various studies in European and American populations. The Indian population is genetically and socially quite different from western populations and the incidence of DVT can also be different.

Concerns have also been expressed regarding efficacy and side effects of various methods used for prophylaxis of DVT. These have made the issue of prophylaxis for DVT controversial. Patients undergoing total hip replacement (THR) and total knee replacement (TKR) are considered at high risk, requiring chemoprophylaxis in the form of low molecular weight heparin (LMWH) according to western and few Asian literatures. However the use of chemoprophylaxis for all the patients has its own disadvantages. Also it makes the treatment costly. Due to lack of studies we have to follow western guideline to prevent DVT in hip and knee arthroplasty. Even in Indian studies, most were conducted in metro cities. Therefore we decided to undertake this prospective study at our institution to determine incidence of DVT in rural population undergoing hip and knee replacement and ways to prevent it.

\section{METHODS}

We carried out a prospective study of 135 cases of total hip and knee replacement over a four year period from January 2009 to January 2013. Out of 135 cases, 78 cases were of total hip and 57 cases were of total knee replacement. Thorough history taking and examination was done and recorded. Presence of any medical problems was documented for a possible correlation with the occurrence of DVT. Any known risk factor for DVT like past history of DVT, preexisting DVT as shown by pre-operative color Doppler report, history of known coagulation disorder, chronic renal/liver disease, revision hip/ knee replacement, presence of varicose veins, morbid obesity, malignancy etc. were checked and those patients were excluded from this study. Regional anesthesia in the form of spinal / epidural was given to patients.

All the patients were not given any form of chemoprophylaxis like low molecular weight heparin i.e. LMWH. They were closely monitored for the clinical signs of DVT like Homan's sign, prominence of superficial vein, leg \& ankle swelling, skin discoloration, fever etc.A strict protocol for mobilization of the patients after the surgery was followed. Patients were encouraged to do toes and ankle movement immediately after surgery. In case of TKR they were mobilized full weight bearing on the second day. All the patients underwent duplex ultrasonographic assessment of both the lower limbs between the $4^{\text {th }}-7^{\text {th }}$ day and on $14^{\text {th }}-16^{\text {th }}$ postoperative day. The Doppler assessment included examination of bilateral common femoral, superficial femoral, popliteal, anterior tibial and posterior tibial veins. They were assessed for flow, visualized thrombus, compressibility and augmentation. A diagnosis of DVT was made where there was visualization of thrombosis, absence of flow, lack of compressibility or lack of augmentation. The thrombus was classified as distal if it involved the calf veins only and as proximal if it involved the popliteal or a more proximal vein. Patients who had both a proximal and a distal thrombus were classified as having proximal thrombosis.

The patients who developed postoperative distal venous thrombosis diagnosed by Doppler examination were closely monitored. However they were not given any form of thrombolytic treatment. The patient who showed evidence of proximal DVT was subjected to standard thrombolytic treatment. $\mathrm{He}$ received infusion of unfractionated Heparin at the rate of 1000 IU per hour. Tab. Warfarin-5 mg per day was started simultaneously. International normalized ratio (INR) and Activated partial thromboplastin time (APTT) was closely monitored. When therapeutic level of INR (between 2 and 3) was achieved, Heparin infusion was stopped. Warfarin was continued for about three months. A repeat Doppler study was performed in all these patients within a week of the first positive Doppler study to make sure that there was no further propagation of the thrombus.

\section{RESULTS}

Out of 135 patients, there were 55 male patients (Average age 68 years) and 80 female patient (Average age 71 years).There were 78 patients $(57 \%)$ of total hip replacement and 57 (43\%) total knee replacement. Out of 78 THR, 45 (58\%) were cemented and 33 (42\%) were uncemented.

Only 5 patient out of $135(3.7 \%)$ were detected to have DVT. Four patients out of five were from above 70 years age group. We observed that DVT developed more commonly following total hip replacement surgery $(\mathrm{n}=$ 4, $5.1 \%)$ compared to total knee replacement $(n=1$, $1.7 \%$ ). Occurrence of DVT was lowest in the patients undergoing total knee replacement. Out of four patient who developed post operative DVT in the THR group, cemented THR was done in three patient( out of 45) i.e. $6.6 \%$ and one patient (out of 33) i.e. $3.03 \%$ with uncemented. Out of five positive cases for DVT, only two had clinical signs of DVT like calf swelling and tenderness. Only 1 patient had proximal thrombus, rest all i.e. 4 had distal thrombi. All the patients with evidence of deep venous thrombosis (both proximal and distal) underwent repeat Doppler study one week after the detection of thrombus to rule out proximal extension of the thrombus. In four patients with distal DVT there was resolution of thrombosis. One patient who showed 
evidence of proximal DVT at the time of first Doppler examination and who was subjected to standard thrombolytic treatment did not show any propagation of thrombus. None of the patients developed clinically evident pulmonary embolism while in hospital or during the first three month following surgery.

\section{DISCUSSION}

Postoperative deep vein thrombosis is a well-recognized complication following major orthopedic surgeries like hip and knee arthroplasty in the western countries. Reviewing the world literature incidence of DVT in relation to the type of orthopedic procedures suggests a great degree of variation. There are few Asian studies on the incidence of DVT. The incidence of DVT reported in these were; Hongkong- $53.3 \%,{ }^{3}$ Thailand- $4 \%{ }^{4}$, Korea$10 \%{ }^{5}$, Singapore- $9.7 \%{ }^{6}$ and Malaysia- $62.5 \% .^{7}$ Lee et al. $^{8}$ have reported $20.1 \%$ incidence of VTE in patients undergoing orthopedic surgery as compared to $30 \%$ in those undergoing general surgery.

In the largest multicentric, centrally audited venographic trial among Asian patients, Piovella et al. ${ }^{9}$ found incidence of DVT to be $41 \%$ in patients undergoing total hip replacement (THR), total knee replacement (TKR) and hip fracture surgery without prophylaxis. ${ }^{8}$ They pointed out that rate of proximal DVT after TKR was $17.1 \%$, which is on higher side of the range reported from western countries.

Unlike western countries incidence and guidelines on DVT prevention in Indian population is not formulated. Particularly rural population who has different lifestyle as compared to urban population incidence of DVT is debatable. As a consequence, thromboprophylaxis is not practiced routinely in this subcontinent. Most of the thrombi in this population have been reported to be distal, which resolve spontaneously without any long-term consequences. ${ }^{7,10,11,12}$ Dhillon et al., ${ }^{7}$ Agarwala et al ${ }^{10}$ and Piovella et al. ${ }^{9}$ reported high incidence of DVT by venography in Asian patients undergoing lower limb surgeries without prophylaxis. On the other hand, Jain et al., ${ }^{13}$ Bagaria et al., ${ }^{14}$ Mavalankar et al., ${ }^{11}$ Atichartakarn et al., ${ }^{4}$ and Mitra et al. ${ }^{6}$ reported a low incidence of DVT by venography in Asian patients undergoing orthopaedic surgeries.

In our study the total incidence of DVT came out to be $3.7 \%$ (5 out of 135). The incidence of DVT in THR came out to be $5.1 \%$ and in TKR came out to be $1.7 \%$. Sex wise distribution came out to be 4 in 80 females $(5 \%)$ and 1 in 57 males $(1.7 \%)$. The incidence of DVT did not associate with BMI (body mass index). However we did not take patient with morbid obesity $(\mathrm{BMI}=40)$ in this study. There was not a single case of pulmonary embolism. These results are comparable to those published by Jain et $\mathrm{al}^{15}$ who had $1.9 \%$ rate of proximal DVT in their series of 106 patients without a single case of pulmonary embolism and with those published by
Bagaria et al., ${ }^{14}$ who reported $6.2 \%$ incidence of DVT. Our results, however, are not in agreement with those published by Agarwala et al., ${ }^{10}$ who reported $60 \%$ incidence of DVT in their patients not receiving any form of chemoprophylaxis. We believe that this difference could be because of the difference in the diagnostic modality used in both studies. While Agarwala et al. used contrast venography, which is the gold standard, for diagnosis of both proximal and distal DVT; we employed duplex sonography for detection of postoperative DVT. Though this is an established diagnostic modality, many authors have questioned its ability to diagnose asymptomatic calf thrombi as it may miss $20 \%$ of isolated calf DVT. ${ }^{16,17}$ So, isolated calf thrombi in some of the patients may not have been picked up by Doppler examination in our study. Also, Agarwala et al do not seem to have elaborated on the venographic evidence of DVT in their patients. Because nonfilling of contrast in deep veins on phlebography is claimed to be an indirect sign of DVT by some authors but rejected by others. Bjorgell et al. ${ }^{18}$ showed that isolated nonfilling of the posterior tibial and/or deep muscle veins of the calf found by phlebography may be an indirect sign of DVT but is equally commonly caused by other pathological conditions like edema, bleedings, ligament and muscle ruptures, Baker cysts, and superficial thrombophlebitis or arises without any detectable explanation. Woolson et $\mathrm{al}^{32}$ suggested that withholding anticoagulation therapy on the basis of the findings of leg sonography is safe despite the fact that sonography is less accurate than contrast venography in detecting calf thrombi.

However most of these studies included trauma cases (hip, pelvi-acetabular, spine), paraplegic cases along with arthroplasty cases.

The incidence of DVT was lower in TKR (1.7\%) than those in THR $(5.1 \%)$ in our study. However Agarwala et $\mathrm{al}^{19}$ stated that the incidence of DVT in patients undergoing total knee arthroplasty was higher than in patients undergoing total hip arthroplasty.

We did not find any correlation between the presence of clinical signs of thrombosis and sonographic evidence of DVT. Out of five, only two patients had clinical features suggestive of DVT. This confirms unreliability of physical signs in the diagnosis of postoperative DVT as shown by Stulberg et al. ${ }^{20}$ All the patients included in our study had their surgery performed under spinal/epidural anesthesia. Though it is claimed by many authors that this can reduce the incidence of DVT, it is difficult to draw this conclusion from our study as all the patients underwent surgery in spinal anesthesia and there was no control to compare the incidence of DVT in patients undergoing surgery under general anesthesia.

As four out of five patients had distal DVT, we decided not to treat them with anticoagulation. Kakkar et al., ${ }^{21}$ have shown that popliteal and femoral clots are precursors to pulmonary emboli. This is in sharp contrast 
to tibial and peroneal clots, which are of little clinical significance with respect to symptomatic emboli. Many other authors have also recommended treating asymptomatic distal DVT by close clinical observation and serial Duplex ultrasound study. ${ }^{22-24}$

Heparin (molecular weight 10000 - 20000) has been fractioned into Low Molecule weight heparin (MW 30007000) by different techniques. LMWH has different anticoagulant profile; selectively inhibit factor $\mathrm{Xa}$ with little effect on factor IIa. They act only by inducing conformational change in AT III and not by bringing together AT III and thrombin. As a result LMWH have smaller effect on aPTT (activated partial thrombin time) and whole blood clotting time than heparin. Also they have lesser ant platelet action - less interference with hemostasis. A lower incidence of hemorrhagic complications compared to heparin has been reported in some studies, but not in others. ${ }^{2}$ LMWH has many potential disadvantages like increase in the total cost of treatment and bleeding complications. Cost of LMWH (Dalteparin, enoxaparin etc) is around Rupees 500- 900 per injection. Most of the centers around the world give these once a day for at least five to seven days. That increases the cost by at least 3000- 5000 rupees.

World over the use of routine chemoprophylaxis i.e. Low- molecular weight heparin like Dalteparin and Enoxaparin for the prevention of DVT/ PE in all joint replacement has been commonly advocated. ${ }^{29,30}$

However Gillespie et al, ${ }^{28}$ Mcnally et $\mathrm{al}^{27}$ and others have disapproved routine use of chemoprophylaxis. Gillespie et $\mathrm{al}^{28}$ stated that the use of pharmacological prophylaxis is for the high-risk patients (advanced age, past history of DVT, presence of varicose veins, obesity, malignancy, immobilization, etc.) in whom the potential benefits clearly appear to outweigh the risks. McNally et al. ${ }^{27}$ have also stated that increased incidence of bleeding complications like excessive bruising around the wound and increased wound bleeding or hematomas with the use of LMWH has prevented their routine use in joint replacement, as was the case with unfractionated heparin in the past.

In India use of LMWH has been questionable. Agarwala et $\mathrm{al}^{19}$ stated that they found LMWH (Dalteparin sodium) a safe and easy to administer thromboprophylactic agent, but agreed that the problems related to excessive bleeding and the cost of the prophylaxis are a major hurdle to its wide acceptance. They also said that use of pressure stockings and early mobilization may be worthwhile in cases where LMWH cannot be used. ${ }^{19,25,26}$ Rajgopal $\mathrm{N}^{31}$ in his study has proven that DVT occurs in Indian patients in spite of prophylaxis therapy with low molecular weight heparin (Dalteparin sodium). Even Malvankar et $\mathrm{al}^{11}$ has recommended use of chemoprophylaxis only in certain high risk cases. Also, if thromboprophylaxis is so important for all the patients, at least a few patients would have required that. None of the patients were subjected to chemoprophylaxis in our study.

We, therefore, wonder how far we are justified in subjecting all the patients undergoing joint replacement to routine chemoprophylaxis which could increase the risk of hematoma formation, infection, a re-operation and a prolonged hospital stay and put more burdens on the already stretched financial resources of the patient.

From our study and those by other Indian authors, ${ }^{11,13,14}$ it appears that DVT and PE in India is not a very frequently encountered problem. We find the sample size of 135 patients in our study to be reasonable. Our study suggests that we may not require LMWH for all hip and knee replacement cases. However we can not be certain whether LMWH is needed in all arthroplasty cases. A multicentre trial with large subject size along with randomized control trials would be needed to solve the dilemma.

\section{CONCLUSION}

We believe that the incidence of DVT in Indian population is debatable and there is not enough evidence for the use of routine chemoprophylaxis in all joint replacement cases for its prevention. Doctor's particularly orthopedic surgeons should be aware about DVT/ PE, its manifestation and complication associated with it. They should keep a close watch with high level of suspicion in joint replacement cases. We advocate use of pharmacological prophylaxis only for the high-risk patients (past history of DVT, presence of varicose veins, morbid obesity, malignancy, immobilization, etc.) in whom the potential benefits clearly appear to outweigh the risks as was advocated by Gillespie et al. ${ }^{28}$

We would not like to make any definite recommendation about chemoprophylaxis only on the basis of our research. Further multicentre trials with large number of patients are needed to formulate guidelines about whether chemo prophylaxis should be given to all joint replacement patients or not.

\section{ACKNOWLEDGEMENTS}

Authors sincerely thank Dr. Harshad Shah, Professor and Head, Department of Radiology, C U Shah Medical College, Surendranagar, Gujarat for help in this study.

\section{REFERENCES}

1. Frederick A. Anderson, H. Brownell Wheeler, Robert J. Goldberg, et al. A Population-Based Perspective of the Hospital Incidence and CaseFatality Rates of Deep Vein Thrombosis and Pulmonary Embolism-The Worcester DVT Study. Arch Intern Med. 1991;151(5):933-938. doi:10.1001/archinte.1991.00400050081016. 
2. Tripathi KD. 6th ed. New Delhi: Jaypee Brothers Medical Publishers (P) Ltd; 2008. Essentials of Medical Pharmacology.

3. Mok CK, Hoaglund FT, Rogoff SM et al. The incidence of deep vein thrombosis in Hong Kong Chinese after hip surgery for fracture of the proximal femur. Br J Surg 1979; 66: 640-42.

4. Atichartakaren V, Pathepchotiwong K, Keorochana S, Eurvilaichit C. Deep vein thrombosis after hip surgery among Thai. Arch Intern Med 1988; 148: 1349-53.

5. Kim YH, Suh JS. Low incidence of DVT after cementless total hip replacement. J Bone Joint Surg [Am] 1988; 70-A: 878-82.

6. Mitra AK, Khoo TK, Ngan CC. Deep vein thrombosis following hip surgery for fracture of the proximal femur. Singapore Med J 1989; 30: 530-32.

7. Dhillon KS, Askander A, Duraiswamy S. Postoperative DVT in Asian patients is not a rarity. J Bone Joint Surg [Br] 1996; 70-B: 427-30.

8. Lee AD, Stephen E, Agarwal S, Premkumar P. Venous thrombo-embolism in India. Eur $\mathbf{J}$ Vasc Endovasc Surg 2009; 37:482-5.

9. Piovella F, Wang CJ, Lu H, Lee K, Lee LH, Lee WC, et al. Deep venous thrombosis rates after major Orthopedic surgeries in Asia. An epidemiological study based on postoperative screening with centrally adjusted bilateral Venography. J Thromb Haemostat 2005; 3:2664-70.

10. Agarwala S, Bhagwat AS, Modhe J. Deep vein thrombosis in Indian patients undergoing major lower limb surgery. Indian J Surg 2003; 65:159-62.

11. Mavalankar AP, Majmundar D, Shubha R. Routine chemoprophylaxis for deep venous thrombosis in Indian patients: is it really justified? Indian J Orthop2007; 41:188-93.

12. Kim YH, Oh SH, Kim JS. Incidence and natural history of deep-vein thrombosis after total hip arthroplasty: a prospective and randomised clinical study. J Bone Joint Surg Br 2003; 85:661-5.

13. Jain V, Dhal AK, Dhaon BK, Pradhan G. Deep vein thrombosis after total hip arthroplasty in Indian patients with and without enoxaparin. J Orth Surg 2004; 12:173-7.

14. Bagaria V, Modi N, Panghate A, Vaidya S. Incidence and risk factors for development of venous thromboembolism in Indian patients undergoing major orthopaedic surgery: results of a prospective study. Postgrad Med J2006; 82:136-9.

15. Jain V, Dhaon BK, Jaiswal A, Nigam V, Singla J. Deep vein thrombosis after total hip and knee arthroplasty in Indian patients. Postgrad Med J 2004; 80:729-31.

16. Gottlieb RH, Widjaja J, Tian L, Rubens DJ, Voci SL. Calf sonography for detecting deep venous thrombosis in symptomatic patients: Experience and review of the literature. J Clin Ultrasound 1999;27: 415-20.
17. Comerota AJ, Katz ML, Hashemi HA. Venous duplex imaging for the diagnosis of acute deep venous thrombosis. Haemostasis 1993; 23:61-71.

18. Bjorgell $\mathrm{O}$, Nilsson PE, Jarenros $\mathrm{H}$. Isolated nonfilling of contrast in deep leg vein segments seen on phlebography and a comparison with color Doppler ultrasound, to assess the incidence of deep leg vein thrombosis. Angiology 2000; 51:451-61.

19. Agarwala S, Bhagwat A S, Wadhwani R. Pre and postoperative DVT in Indian patients - Efficacy of LMWH as a prophylaxis agent. Indian $\mathbf{J}$ Orthop 2005; 39:55-8.

20. Stulberg BN, Insall JN, William GW, Ghelman B. Deep vein thrombosis following total knee replacement: An analysis of six hundred and thirty eight arthroplasties. J Bone Joint Surg Am 1984; 66:194-201.

21. Kakkar VV, Howe CT, Flanc C, Clarke MB. Natural history of postoperative deep-vein thrombosis. Lancet 1969; 2:230-2.

22. Solis MM, Ranval TJ, Nix ML, Eidt JF, Nelson CL, Ferris EJ, et al. Is anticoagulation indicated for asymptomatic postoperative calf vein thrombosis? J Vasc Surg 1992; 16:414-9.

23. Sharpe RP, Gupta R, Gracias VH, Pryor JP, Pieracci FM, Reilly PM, et al. Incidence and natural history of below-knee deep venous thrombosis in high-risk trauma patients. J Trauma 2002; 53:1048-52.

24. Oishi CS, Grady-Benson JC, Otis SM, Colwell CW Jr, Walker RH. The clinical course of distal deep venous thrombosis after total hip and total knee arthroplasty, as determined with duplex ultrasonography. J Bone Joint Surg Am 1994; 76: 1658-63.

25. Thomas DP. Prophylaxis against Deep-Vein Thrombosis following Total Hip Replacement. J Bone Joint Surg (Br). 82: 469-472. 2000.

26. A.J.Best, S.Williams, A. Crozier, R. Bhatt, P.J. Gregg, A.C.W.Hui. Graded compression stockings in elective Orthopaedic surgery. J Bone Joint Surg (Br).2000; 82: 116-118.

27. McNally MA, Cooke EA, Harding ML, Mollan RA. Attitudes to and utilization of, low molecular weight heparins in joint replacement surgery. J R Coll Surg Edinb 1997; 42:407-9.

28. Gillespie W, Murray D, Gregg PJ, Warwik D. Risks and benefits of prophylaxis against venous thromboembolism in orthopaedic surgery. $\mathrm{J}$ Bone Joint Surg Br 2000; 82:475-9.

29. Anthonie W. A. Lensing, MD, PhD; Martin H. Prins, MD, PhD; Bruce L. Davidson, MD, MPH; Jack Hirsh, MD. Treatment of Deep Venous Thrombosis With Low-Molecular-Weight Heparins -A Meta-analysis Arch Intern Med. 1995; 55(6):601607.doi:10.1001/archinte.1995.00430060059007.

30. Howard AW, Aaron SD. Low molecular weight heparin decreases proximal and distal deep venous thrombosis following total knee arthroplasty. A 
meta-analysis of randomized trials. Thromb Haemost. 1998 May;79(5):902-6.

31. Rajagopalan N. Thromboprophylaxis by dalteparin sodium in elective major orthopaedic surgery A multicentric Indian study. Indian J Orthop 2003; $37: 4$.
32. Woolson ST. The resolution of deep venous thrombosis that occurs after total joint arthroplasty. A study of thrombi treated with anticoagulation and observed by repeat venous ultrasound scans. Clin Orthop Relat Res 1994;(299):86-91.

doi:10.5455/2319-2003.ijbcp20130819

Cite this article as: Chandak NS, Gandhi S, Patel B, Rathwa Y. The use of routine chemoprophylaxis for deep vein thrombosis in all patients undergoing hip and knee replacements in rural population - whether it is justified? Int J Basic Clin Pharmacol 2013;2:44651. 